\title{
Pap Smear
}

National Cancer Institute

\section{Source}

National Cancer Institute. Pap Smear. NCI Thesaurus. Code C17348.

A biospecimen collection and staining procedure in which secretions and superficial cells

of the cervix are collected and stained with the Papanicolaou stain followed by

microscopic examination to identify the presence of abnormal cells. 